http://jmscr.igmpublication.org/home/

ISSN (e)-2347-176x ISSN (p) 2455-0450

crossref DOI: https://dx.doi.org/10.18535/jmscr/v8i6.22

Journal Of Medical Science And Clinical Research

\title{
The efficacy of transvaginal ultrasonography and colour doppler in evaluation of adnexal masses
}

\author{
Authors \\ Dr Preety Soni ${ }^{1}$, Dr Rupam Sinha ${ }^{2}$ \\ ${ }^{1}$ Senior Resident, Department of Obstetrics \& Gynaecology, Patna Medical Collage, Aryabhata Knowledge \\ University, Patna, Bihar, India \\ ${ }^{2}$ Associate Professor, Department of Obstetrics \& Gynaecology, Patna Medical Collage, Aryabhata \\ Knowledge University, Patna, Bihar, India \\ Corresponding author \\ Dr Rupam Sinha
}

Associate Professor, Department of Obstetrics \& Gynaecology, Patna Medical Collage, Aryabhata

Knowledge University, Patna, Bihar, India

\begin{abstract}
Objective: The objective of this study is to evaluate the transvaginal ultrasound and colour doppler sonography for differentiation between benign and malignant adnexal masses.

Methods: In this study total 100 patients were selected from gynaecology OPD. At the end of this study there were 84 patients left and with some having bilateral adnexal masses, so total of 112 adnexal masses were evaluated. The transvaginal ultrasound (TVS) was used to study morphology of the adnexal masses and scoring was assigned using De Priest scoring system. The colour doppler study (CD-study) evaluates the presence or absence of blood flow within the adnexal mass, whether the flow is central or peripheral and the resistance index of the flow. The combined TVS morphological scoring and colour doppler study $(T V S+C D)$ were used for evaluating the adnexal masses. The confirmatory diagnosis was made either by histopathological examination or fine needle cytological examination. The accuracy of TVS-morphological study and colour doppler sonography for differentiation of adnexal masses were assessed by calculating sensitivity, specificity, positive predictive value and negative predictive value.

Conclusion: TVS-morphological scoring is one of the best tools for adnexal mass evaluation but when it is combined with colour doppler sonography its diagnostic accuracy increases.

Keywords: transvaginal ultrasound, colour doppler sonography, adnexal masses.
\end{abstract}

\section{Introduction}

The adnexal mass is one of the commonest clinical presentations in gynaecological practice. The differential diagnosis of adnexal mass varies from simple cyst to malignant mass of various abdominal and pelvic organs ${ }^{1}$. The differentiation between benign and malignant adnexal mass is a great diagnostic challenge for gynaecologists; as adnexal structures are relatively inaccessible and there is non-specific symptomology ${ }^{2}$. The surgery is often required solely to exclude the possibility of malignancy. The ovarian malignancy is the second most common malignancy and the leading cause of death. The one third of the patient subjected to surgery turned out to have benign mass. An accurate diagnosis is essential to 
establish optimal treatment of these patients. There is need for non-invasive tool to differentiate between benign and malignant adnexal masses. The different non- invasive tools are tumor markers, transvaginal ultrasonography, colour doppler sonography, other radiological modalities and multimodal diagnostic tools ${ }^{3}$.

Materials and Methods

This is a prospective cohort study. Total 100 patients with adnexal masses were selected from gynaecological OPD register from April 2019 to April 2020 in the department of obstetrics and gynaecology of Patna medical college and hospital, Patna.

The exclusion criteria are-

- Pregnant women

- Patients having H/O ovarian malignancy

- Patients having H/O uterine malignancy
- Patients having $\mathrm{H} / \mathrm{O}$ endocrinological abnormality

Each patient was subjected to proper history taking with emphasis on age, signs and symptoms, menstrual status, parity and past or family history of malignancy. The general examination was done for each patient. Bimanual pelvic examination was done for each patient.

Transvaginal ultrasonography (TVS) was done for each patient by Siemens -Sonoline USG machine with transvaginal probe (7.5 MHZ). The parameters that were taken into consideration are-

1. Volume of the mass-width $\mathrm{x}$ height $\mathrm{x}$ thickness

2. Cyst wall structure

3. Septa structure

According to above three parameters morphological scoring was done using De Priest scoring system ${ }^{4}$.

De Priest scoring system

\begin{tabular}{|l|c|c|c|c|}
\hline Scores & 0 & 1 & 3 & 4 \\
\hline Volume $(\mathrm{cm} 3)$ & $<10$ & $10-50$ & $>50-200$ & $>500$ \\
\hline $\begin{array}{l}\text { Cyst wall } \\
\text { structure }\end{array}$ & $\begin{array}{c}\text { Smooth, }<3 \mathrm{~mm} \\
\text { thickness }\end{array}$ & $\begin{array}{c}\text { Smooth, }>3 \mathrm{~mm} \\
\text { thickness }\end{array}$ & $\begin{array}{c}\text { Papillary } \\
\text { projections }>=3 \mathrm{~mm}\end{array}$ & $\begin{array}{c}\text { Predominantly } \\
\text { solid }\end{array}$ \\
\hline $\begin{array}{l}\text { Septal } \\
\text { structure }\end{array}$ & No septa & $\begin{array}{c}\text { Thin septa } \\
<3 \mathrm{~mm}\end{array}$ & Thick septa3mm-1cm & $\begin{array}{c}\text { Predominantly } \\
\text { solid }\end{array}$ \\
\hline
\end{tabular}

According to this scoring system score was given to each mass and mass was classified into benign mass if score is $<5$ and malignant if score was $>=5$.

According to morphological features of adnexal mass the masses were classified into groups as follows-

1. Unilocular

2. Unilocular solid

3. Multilocular

4. Multilocular solid

5. Solid

Colour doppler ultrasonography-after having an idea about morphological feature of adnexal mass blood flow evaluation of mass was done and parameters that are taken into consideration are-

1. Blood flow-present or absent

2. Localization of blood flow-peripheral or central
3. About blood flow-scanty, moderate or abundant

4. Resistance index- defined as difference between the peak systolic and end diastolic flow velocities, divided by the peak systolic velocity measured.

The adnexal mass was differentiated into benign mass if the doppler study were as follows-

1. No flow detected in colour doppler ultrasonography

2. If flow was present the resistance index is $<=0.40$

The adnexal mass was differentiated into malignant mass if doppler study was as follows-

1. Presence of either central or peripheral flow with resistance index $>0.40$

Histological diagnosis- The confirmatory diagnosis was made by histopathological 
examination of the adnexal masses after laparotomy. The accuracy of transvaginal ultrasound and colour doppler ultrasonography were evaluated by calculating sensitivity, specificity, positive predictive value and negative predictive value for each method.

\section{Results}

In this study total 100 patients were selected. A total of 16 patients were excluded from the study because in 8 patients adnexal masses vanished in 3 months of follow up, 5 patients did not turn up for follow up3 patients died during the course of study. In 84 patients, 71 patients underwent laparotomy and histopathological examination of the laparotomy specimen and in 13 patients fine needle aspiration cytology of mass was done. There were bilateral adnexal masses in 28 patients, so total numbers of adnexal masses evaluated were 112 .

Table 1 Age wise distribution of benign and malignant adnexal masses

\begin{tabular}{|l|c|c|}
\hline Age & $\begin{array}{c}\text { Total no. of } \\
\text { Benign masses }\end{array}$ & $\begin{array}{c}\text { Total no. of } \\
\text { malignant masses }\end{array}$ \\
\hline$<20$ years & $40 \%$ & $60 \%$ \\
\hline $20-44$ years & $85.2 \%$ & $14.7 \%$ \\
\hline$>45$ years & $58.5 \%$ & $41.46 \%$ \\
\hline
\end{tabular}

The adnexal masses were more common in 20-44 years of age group. The mean age for benign masses is 35 years (SD-2.3 years). The mean age for malignant masses is 48 years (2.6 years).

Table 2 Distribution of adnexal masses according to menopausal status

\begin{tabular}{|l|c|c|}
\hline & Premenopausal patients & Postmenopausal patients \\
\hline Benign mass & $91.5 \%$ & $8.5 \%$ \\
\hline Malignant mass & $56 \%$ & $44 \%$ \\
\hline
\end{tabular}

In this study benign masses and malignant masses both are common in premenopausal patients.

Table 3 Statistical analysis of TVS-morphological scoring in evaluating adnexal masses

\begin{tabular}{|l|c|c|c|}
\hline $\begin{array}{l}\text { TVS-morphological } \\
\text { score }\end{array}$ & $\begin{array}{c}\text { Histological } \\
\text { Malignant masses }\end{array}$ & $\begin{array}{c}\text { Confirmation } \\
\text { Benign masses }\end{array}$ & Total \\
\hline Malignant masses & 24(true positive) & 12(false positive) & 34 \\
\hline Benign masses & 10 (false negative) & 68(true negative) & 78 \\
\hline Total & 32 & 80 & 112 \\
\hline
\end{tabular}

The sensitivity of TVS-morphological scoring is $68.75 \%$, specificity is $85 \%$, positive predictive value is $64.7 \%$, negative predictive value is $87.17 \%$.

Table 4 Statistical analysis of colour doppler sonography in evaluating adnexal masses

\begin{tabular}{|l|c|c|c|}
\hline $\begin{array}{l}\text { Diagnosis on basis of } \\
\text { Colour doppler } \\
\text { sonography }\end{array}$ & $\begin{array}{c}\text { Histological } \\
\text { Malignant masses }\end{array}$ & $\begin{array}{c}\text { Confirmation } \\
\text { Benign masses }\end{array}$ & Total \\
\hline Malignant mass & 25(true positive) & 15(false positive) & 40 \\
\hline Benign mass & 7 (false negative) & 65(true negative) & 72 \\
\hline Total & 32 & 80 & 112 \\
\hline
\end{tabular}

The sensitivity of colour doppler sonography is $78.12 \%$, the specificity is $81.25 \%$, positive predictive value is $62.50 \%$, the negative predictive value is $90.27 \%$. 
Table 5 Statistical analysis of combined TVS-scoring and colour doppler sonography in evaluating adnexal masses.

\begin{tabular}{|l|c|c|c|}
\hline $\begin{array}{l}\text { Diagnosis by combined } \\
\text { TVS -scoring and colour } \\
\text { doppler sonography }\end{array}$ & $\begin{array}{c}\text { Histological } \\
\text { Malignant masses }\end{array}$ & $\begin{array}{c}\text { Confirmation } \\
\text { Benign masses }\end{array}$ & Total \\
\hline Malignant masses & 29(true positive) & 15(false positive) & 44 \\
\hline Benign masses & 3 (false negative) & 65 (true negative) & 68 \\
\hline Total & 32 & 80 & 112 \\
\hline
\end{tabular}

The sensitivity of combined method is $90.6 \%$, the

is $65.90 \%$, the negative predictive value is specificity is $81.25 \%$, the positive predictive value $95.58 \%$.

Table 6 Comparison of TVS-study, CD-study, TVS+CD-study in evaluating adnexal masses

\begin{tabular}{|l|c|c|c|c|}
\hline & Sensitivity & Specificity & $\begin{array}{c}\text { Positive } \\
\text { predictive value }\end{array}$ & $\begin{array}{c}\text { Negative } \\
\text { predictive value }\end{array}$ \\
\hline TVS-study & $68.75 \%$ & $85 \%$ & $64.70 \%$ & $87.17 \%$ \\
\hline CD-study & $78.12 \%$ & $81.25 \%$ & $62.50 \%$ & $90.7 \%$ \\
\hline TVS+CD-study & $90.6 \%$ & $81.25 \%$ & $65.90 \%$ & $95.58 \%$ \\
\hline
\end{tabular}

This table shows that TVS+CD-study has the highest sensitivity, positive predictive value and negative predictive value whereas specificity is highest in TVS-study group.

\section{Discussion}

In this study the adnexal masses were more common in 20-44 years of age but malignant masses were more common in $>45$ years of age. In this study malignant masses were more common in premenopausal women whereas in De priest et al study the malignant masses were more common in postmenopausal patients. This may be due to the fact that the sample size is small and maximum number of patients was in age group of 20-44 years.

The efficacy of TVS-morphological scoring for differentiation of benign and malignant masses is reflected by the sensitivity of $68.75 \%$, specificity of $85 \%$, and positive predictive value of $64.70 \%$ and negative predictive value of $87.17 \%$. In the study of Alcazar et al the sensitivity is $100 \%$, specificity is $81.4 \%$, the positive predictive value is $73.8 \%$, and negative predictive value is $100 \%$. Thus in this study it is seen that sensitivity is low, this may be because the parameters that were used in scoring system were not evaluated by univariate or multivariate analysis. Thus it was not certain that that how much each parameter was predictor of malignancy. The other reason may be that the USG is highly operator and equipment dependent.

In present study the colour doppler study shows the sensitivity of $78.12 \%$, specificity of $81.25 \%$, the positive predictive value of $97 \%$, negative predictive value of $90.7 \%$. In the study of Weiner et al study the sensitivity is $94 \%$, specificity is $97 \%$, positive predictive value is $97 \%$ and negative predictive value is $94 \%$. The reason behind difference in accuracy of both studies of colour doppler are due to the cut-off value of resistive index, the phase of menstrual cycle when the study was undertaken and the vessel which was studied i.e ovarian vessel or intratumoral vessel.

The combined TVS-morphological scoring and colour doppler sonography shows sensitivity of $90.6 \%$, specificity is $81.25 \%$, positive predictive value is $65.90 \%$ and negative predictive value is 95.58\%. While the Alcazar et al shows the sensitivity of $100 \%$, specificity of $94.9 \%$, positive predictive value of $91.2 \%$ and negative predictive value of $100 \%$.

The study done by Ozcan et al combined transvaginal ultrasound and CA125 tumor marker, along with menopausal status and ascites is used 
to distinguish adnexal masses. In this study TVS shows the positive predictive value of $94.19 \%$ and negative value of $98.22 \%$. $^{7}$

This study suggests that colour doppler sonography increases the sensitivity and negative predictive value with slight decrease in specificity and positive predictive value. This is due to the fact of that there were high false positive results but low false negative results. When both TVSmorphological scoring and colour doppler sonography were combined the sensitivity and negative predictive value increases due to further decrease in false negative results. The specificity and positive predictive value are almost similar to TVS-morphological scoring and colour doppler sonography.

\section{Conclusion}

The advances in non-invasive evaluation of adnexal masses by transvaginal and colour doppler sonography decreases the morbidity and mortality of patients suffering by adnexal masses. The TVS-morphological scoring is one of the best non-invasive tools for differentiation of benign and malignant adnexal masses. When colour doppler study is combined with the morphological scoring the diagnostic accuracy increase. The treatment modality should be decided according to the clinical parameters and sonography evaluation.

\section{References}

1. Davies AP, Jacob I, Woolas R et al. The adnexal mass: benign or malignant? Evaluation of a risk of malignant index. $\mathrm{Br}$ J Obstet Gynaecol 1993; 100:927-31.

2. D H Oram, I j Jacobs, J L Brady, A Prysdavies. Early diagnosis of ovarian cancer. British journal of hospital medicine 1997; 44:320-324.

3. Adam Rosenthal Jan Jacobs. Over view of ovarian cancer screening. Recent advances in Obstetrics and gynaecology. 2005; $23^{\text {rd }}$ Recent: pp 246-250.
4. P. D. De Priest, Shenson, and et al. A morphological index based on sonographic findings in ovarian cancer. Gynaecological oncology; 1993;51;7-11

5. Juan Luis Alcazar, MD, Luis T. Merce, MD, Carmen Laparte, MD, Matias Jurado, MD. A new scoring system to differentiate benign and malignant adnexal masses. Am J Obstet Gynaecol 2003; 188;685-92.

6. Zeev Weiner, Israel Thaler and et al. differentiating malignant and from benign ovarian tumors with transvaginal colour flow imaging. Obstetrics and gynaecol 1992; 79; 159-62.

7. HOzcan, O Balatetal and et al. The management of adnexal masses in premenopausal patients: A ten years retrospective study at a single centre. EUR J Gynaecol Oncol 2017; 38(3):372-377. 